\title{
Ascorbic acid prevents cimetidine-induced decrease of serum hydrocortisone concentrations
}

\author{
Marinus P. Boidin, Arie Stuurman and Wilhelm Erdmann
}

\section{Introduction}

Cimetidine (Tagamet ${ }^{\boxplus}$, Smith Kline \& French, Rijswijk, the Netherlands) is a major histamine $\mathrm{H}_{2}$ receptor antagonist. Intravenously, it has been advocated in critical and intensive-care medicine for the prevention of stress ulcers. Few side-effects of clinical importance, apart from gynaecomastia, have been reported [1]. Antiandrogenic effects of cimetidine have been reported [2]. Recently, it has been reported that cimetidine can decrease serum hydrocortisone concentrations in man [3].

Imidazoles, cimetidine, and etomidate (Hypnomidate ${ }^{\circledR}$, Janssen, Beerse, Belgium), can bind to cytochrome P-450 at the active haem structure [45]. This causes a blockade of the cytochrome with a concomitant decrease of the serum hydrocortisone concentrations. Cytochrome P-450 proves to be essential for the $20-22$ hydroxylation of cholesterol, the precursor for many steroid hormones [6]. Administration of cimetidine may result in low serum hydrocortisone concentrations. Intravenous administration of ascorbic acid is supposed to protect the serum hydrocortisone concentrations in patients whose steroid synthesis is inhibited by imidazoles [7]. The reason for this phenomenon is yet undetermined.

This prospective, blind, parallel study was designed to establish the effect of ascorbic acid on human hydrocortisone concentrations after cimetidine administration.

\section{Methods}

20 Consecutive male patients entered this study. Any patients suffering from renal, hepatic or endocrinological diseases and patients using corticosteroid drugs, $\mathrm{H}_{2}$ antagonists or any other imidazole including drug, in a period of four weeks prior to surgery, were excluded from the study population. Patients with incomplete data, because of short duration of surgery, were omitted. Patients receiving fresh frozen plasma were excluded from the study population. After exclusion for these criteria, 16 patients remained. These patients were randomly devided into two groups for a parallel-blind investigation.

All patients were scheduled for major abdominal vascular surgery lasting longer than $3.5 \mathrm{~h}$. The study procedure and conditions were kept as uniform as possible. All procedures were scheduled for 08.00 and followed the same course during the morning. All patients needed invasive monitoring and intensive care postoperatively during $24 \mathrm{~h}$. Informed consent was obtained from all patients the day before surgery and the study was in accordance with the standards of the hospital ethical committee, which bases it decisions on the Helsinki Declaration.

An epidural catheter was inserted between the third and fourth vertebra on the day prior to surgery. No premedication was given. Anaesthesia was induced with methohexital $1 \mathrm{mg} / \mathrm{kg}$ (Brietal ${ }^{\oplus}$, Lilly, Nieuwegein, the Netherlands), piritramide $0.2 \mathrm{mg} / \mathrm{kg}$ (Dipidolor ${ }^{\circledR}$, Janssen) and pancuronium bromide $1 \mathrm{mg} / \mathrm{kg}$ (Pavulon ${ }^{\circledR}$, Organon, Oss, the Netherlands). Patients were ventilated throughout the surgical procedure. Bupivacaine $0.1 \mathrm{ml} / \mathrm{kg}$ (Marcaine ${ }^{\circledR}$, Astra, Rijswijk, the Netherlands) was administered via the epidural catheter at the time of induction. The radial artery and the subclavian vein were cannulated. This induction period lasted for approximately $20 \mathrm{~min}$. The normal hydrocortisone profile of this

\section{Keywords}

Ascorbic acid

Cimetidine

Cytochrome P-450

Hydrocortisone

Metabolism

Steroid hydroxylases

Dr. M.P. Boidin and

Dr. W. Erdmann: Department of Anaesthesiology, Erasmus University Rotterdam, P.O. Box 1738, 3000 DR Rotterdam, the Netherlands.

A. Stuurman (correspondence): Department of Hospital Pharmacy, Foundation Ignatius Hospital Breda, Wilhelminasingel $33,4817 \mathrm{JX}$

Breda, the Netherlands.
Boidin MP, Stuurman A, Erdmann W. Ascorbic acid prevents cimetidine-induced decrease of serum hydrocortisone concentrations. Pharm Weekbl [Sci] 1990;12(5):151-3.

\begin{abstract}
A blind, parallel, prospective, clinical study was conducted to investigate the effect of ascorbic acid on human serum hydrocortisone concentrations which were decreased by the administration of cimetidine. The study population included 16 male adults scheduled for major abdominal vascular surgery. The study was conducted in surgical patients under anaesthesia, in which steroidogenesis was inhibited by cimetidine. The results showed a reduction in serum hydrocortisone concentrations in patients receiving a placebo. In patients receiving ascorbic acid, there was a significant increase in serum hydrocortisone concentration. This reflects the normal serum hydrocortisone profile for this operation and anaesthetic technique. Cimetidine can bind to cytochrome P-450 covering the active haem group, the cytochrome proves to be of vital importance for hydroxylation reactions, involved in human steroidogenesis. Serum hydrocortisone concentrations will decrease when cytochrome P-450 becomes blocked. Intravenous administration of ascorbic acid was supposed to cause relief for this decrease. The reasons are undetermined yet. This investigation proved that ascorbic acid can prevent cimetidine-induced decrease of human serum hydrocortisone concentrations.
\end{abstract}

Accepted 7 June 1990. 
Table 1

Demographic data of the study population

\begin{tabular}{|c|c|c|c|}
\hline Group & $\mathrm{A}$ & B & $\mathrm{C}$ \\
\hline Drugs & $\begin{array}{l}\text { cimetidine } \\
\text { with placebo }\end{array}$ & $\begin{array}{l}\text { cimetidine with } \\
\text { ascorbic acid }\end{array}$ & $\begin{array}{l}\text { control } \\
\text { group }\end{array}$ \\
\hline Patients & 8 & 8 & 8 \\
\hline Age (years) (SD) & $65 \quad(8.1)$ & $68 \quad(9.1)$ & $66 \quad(7.3)$ \\
\hline Weight (kg) (SD) & $73 \quad(9.1)$ & $72 \quad(9.6)$ & $74 \quad(9.3)$ \\
\hline Surgery (h) & $5.7(4.2-7.3)$ & $6.3(5.2-8.2)$ & 5.5 \\
\hline Blood loss (l) & $1.7(1.1-2.3)$ & $1.9(1.3-2.7)$ & $2.1(1.6-2.5)$ \\
\hline
\end{tabular}

Figure 1 Serum hydrocortisone concentrations after placebo (group A: black) and after ascorb acid (group B: shaded) administration. Steroidogenesis was inhibited by cimetidine (400 mg) in both groups. Mean and standard deviation

*: $P<0.01$

anaesthetic technique is exactly known. The values of this historic control group, which were recorded in the same settings and in the same laboratories, were considered sufficiently reliable to serve as the control values for this study.

Physiological parameters, electrocardiogram, arterial systolic and diastolic blood pressures, central-venous mean pressure, heart rate, core temperature and urinary output, were monitored continuously. Blood, plasma expanders and electrolyte solutions for intravenous infusion, were administered as appropriate. Cloxacillin $1000 \mathrm{mg}$ (Orbenin ${ }^{\circledR}$, Beecham, Amstelveen, the Netherlands) was given intravenously to all patients, as a prophylactic antibiotic. No corticosteroid or any other drugs were given, except analgesics and muscle relaxants necessary for the maintenance of anaesthesia. Serum samples were taken before induction of anaesthesia and at 60,120 and 180 min after cimetidine administration. All samples were immediately stored on ice, centrifuged and frozen as soon as possible. After collection of the samples, all patients received $1000 \mathrm{mg}$ fresh ascorbic acid intravenously.
Serum hydrocortisone concentration $\mathrm{nmol} / 1^{-1}$

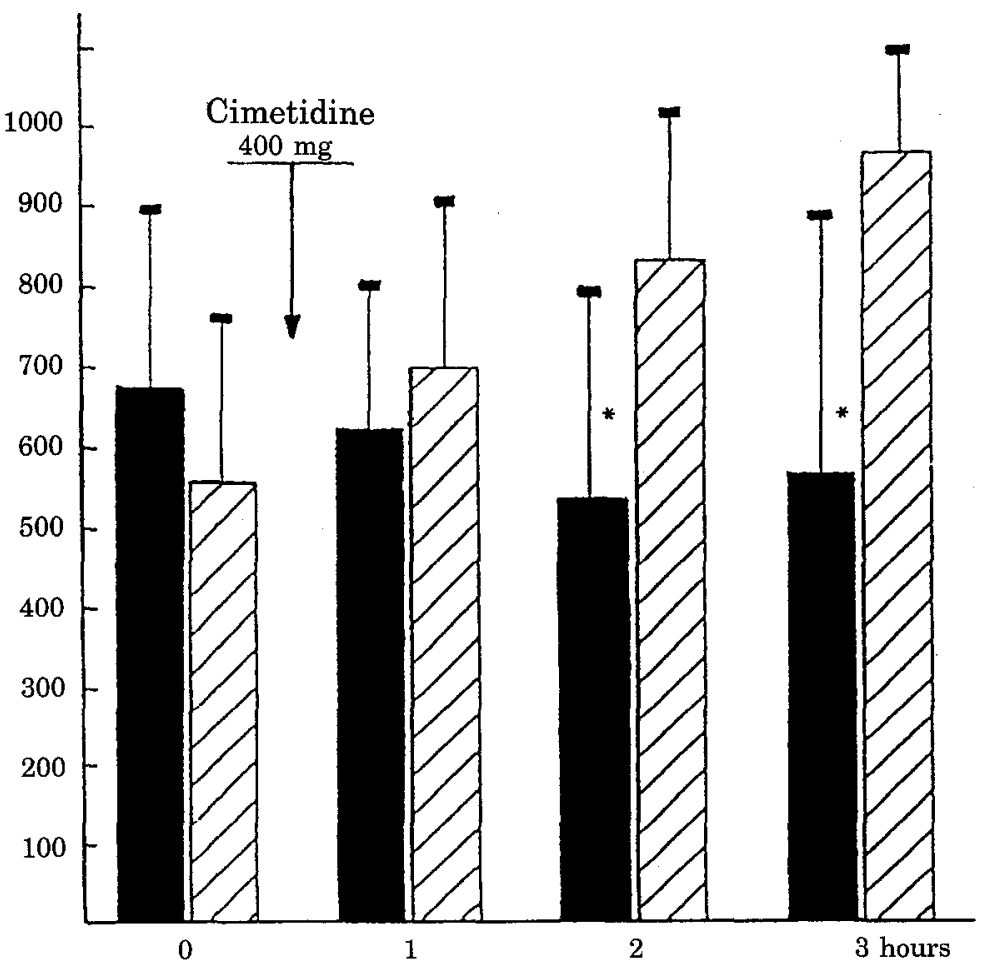

$400 \mathrm{mg}$ Of cimetidine was given as a slow intravenous bolus injection at the end of the induction of anaesthesia. In the contralateral arm a continuous drip infusion of $100 \mathrm{ml}$ saline was started with either $10 \mathrm{ml}$ of saline as a placebo (group A) or $10 \mathrm{ml}$ fluid with $1000 \mathrm{mg}$ of ascorbic acid (group B). The drip ran at twelve drops/min via an infusion pump (IVAC 300). This resulted in the administration of $100 \mathrm{ml}$ fluid over $3 \mathrm{~h}$. The administration code, registered in the hospital pharmacy department, could be obtained when necessary for clinical reasons.

Measurement of serum hydrocortisone concentration was made with the Coat-A-Count RIA Kit (Diagnostic Products Corporation, Los Angeles, USA). Within-run precision in the normal range $(150-550 \mathrm{nmol} / 1)$ is $4 \%$. Interassay precision in the same range is $8 \%$. The least detectable level is $5 \mathrm{nmol} / \mathrm{l}$. There is $65 \%$ cross-reactivity with prednisolone. Neither severe icterus, gross haemolysis, nor severe lipaemia have any effect on the procedure.

Mean values of samples taken at 60, 120 and $180 \mathrm{~min}$ in each group were compared with the pre-operative value. Statistical differences of the mean values were calculated with the one way analysis of variance [8].

\section{Results}

The two groups of 8 patients were comparable for demographic data (Table 1). Physiologic parameters in both groups showed no different mean values during anaesthesia. Arterial systolic, diastolic and mean pressures, central venous blood pressure, urine output and temperature showed essentially the same values in both groups. There were no major clinical differences between the two groups during the first $4 \mathrm{~h}$ of surgery.

In group A (placebo) there was a gradual decrease in serum hydrocortisone concentration. 3 Out of 8 patients reached levels beyond the low normal values. 7 Patients showed a decrease in serum hydrocortisone levels ranging from $0-60 \%$. 1 Patient, however, showed a $30 \%$ increase in serum hydrocortisone concentration (Fig. 1).

In group B (ascorbic acid) there was a gradual increase of the serum hydrocortisone concentrations in the time. The increase is significant from the second hour until the end of the study period. All patients showed increased serum hydrocortisone levels ranging from 15 to just over $100 \%$. Intergroup comparison demonstrated significant $(\mathrm{P}<0.001)$ lower values in group $\mathrm{A}$ (placebo) when compared to group B (ascorbic acid).

\section{Discussion}

The moderate but significant increase in serum hydrocortisone concentrations is in accordance with the findings of Oyama and Takiguchi reporting on patients under spinal anaesthesia [9]. The normal hydrocortisone profile of this operation and anaesthetic technique in our hospital shows a slow but graduate increase of the serum hydrocortisone concentrations. The increase of the mean value proved to be from $56 \mathrm{nmol} / 1^{-1}$ to $97 \mathrm{nmol} / \mathrm{l}^{-1}$ after $3 \mathrm{~h}$.

Administration of ascorbic acid appears to 
have a protective effect on the serum hydrocortisone concentrations of patients who have received cimetidine intravenously. The reason for this phenomenon is not determined yet. The results of this study confirm the observations in previous studies. The serum hydrocortisone concentrations are comparable with the normal hydrocortisone profile for this operation and anaesthetic technique.

According to the manufacturer of cimetidine [Smith Kline \& French, personal communication], no long-term animal studies have been performed to investigate the effects of cimetidine on serum hydrocortisone concentrations. Carlson and Ippoliti [10] found no negative effects on steroidogenesis in patients receiving cimetidine. Feely et al. [11] reported decreased levels of corticosteroid degradation products and aldosterone in the urine of patients receiving cimetidine. Kenyon et al. [12] published an in vitro study on the various effects of cimetidine and ranitidine (Zantac ${ }^{\circledR}$, Glaxo, Nieuwegein, the Netherlands) in isolated bovine adrenal cells. Cimetidine concentrations greater than $200 \mu \mathrm{g} / \mathrm{ml}$ resulted in a $50 \%$ inhibition of hydrocortisone synthesis. With ranitidine, this effect only became apparent at $2000 \mu \mathrm{g} / \mathrm{ml}$. De Natale et al. [13] suggested that bolus injections of cimetidine could temporarily suppress normal corticosteroid production. Recent evidence shows that cimetidine can block steroid synthesis in man [3]. In a double-blind study it was demonstrated that cimetidine decreased serum hydrocortisone concentrations. The same effect could not be demonstrated with ranitidine. This effect has only been observed in anaesthesia; probably because the feedback mechanism is blunted by the anaesthetic technique. Because of the anaesthetic technique, hydrocortisone is not increased by neurological stimuli caused by pain and surgical stress or awakeness.

It has been shown that ascorbic acid can restore the hydrocortisone synthesis in case of hypnomidate toxicity [14]. Also in the case of cimetidine toxicity there was a restoration of the serum hydrocortisone concentration after administration of ascorbic acid [3]. The mechanism is presently under investigation. Hornsby looked at the 11-beta-hydroxylase activity [15]. He suggested that ascorbic acid is a protective compound for cytochrome because $5 \mathrm{~m} M$ ascorbate prevented the rate of loss of 11-beta-hydroxylase activity in the presence of hydrocortisone. But no fitting explanation has been suggested at present.

The question remains as to whether or not these results have any clinical consequences. In the opinion of the authors it is highly probable that they have. Malnourished and postoperative patients, or patients for any reason treated solely with dextrose or electrolyte-containing infusion fluids, run a high risk of catching an illness when cimetidine is prescribed. Without proper substitution of ascorbic acid the possibility exists that an acute addisonian crisis may develop. Such a situation has been reported in the case of administration of etomidate [16].

\section{Conclusions}

Ascorbic acid appears to increase the serum hydrocortisone concentrations in patients under anaesthesia, when the steroidogenesis is inhibited by cimetidine. It is unclear from the presented data what the clinical implication will be for these patients.

\section{Acknowledgements}

The authors wish to thank Dr. R.A.E. Wirtz (vascular surgeon) for his kind permission to perform this study in patients primarily under his care.

\section{References}

1 Dell Fave GF, Tamburrano G, De Magistris L. Gynecomastia with cimetidine. Lancet 1978;1:1319.

2 Winters SJ, Banks JL, Loriaux DL. The histamine H-2 antagonist cimetidine is an antiandrogen. Gastroenterology 1987;76:504-8.

3 Boidin MP, Stuurman A, Erdmann W. Inhibition of steroidogenesis by cimetidine in man. Scand $J$ Gastroenterol 1988;23:(Supp1 154):41.

4 Somogy A, Gugler R. Drug interactions with cimetidine. Clin Pharmacokinet 1982;7:23-41.

5 Wagner RL, White PF, Kan PB, Rosenthal $\mathrm{MH}$, Feldman D. Inhibition of adrenal steroid genesis by the anesthetic etomidate. N Engl J Med 1984;310: L1415-21.

6 Van Thiel DH, Galaver JS, Smith WI, Paul G. Hypothalamic-pituitary-gonadal dysfunction in man using cimetidine. N Engl J Med 1979;300:1012-5.

7 Boidin MP. Steroid response to ACTH and to ascorbic acid during infusion of etomidate for general surgery. Acta Anesthesiol Belg 1985;36:15-22.

8 Godfrey K. Statistics in practice. N Engl J Med 1985;313:1450-6.

9 Oyama T, Takiguchi M. Plasma levels of cortisol in man during spinal anaesthesia and surgery. Can Anaesth Soc J 1970;17:234-8.

10 Carlson HE, Ippoliti AF. Cimetidine, an H-2 antihistamine stimulates prolactin secretion in man. J Clin Endocrinol Metab 1977;45:367-70.

11 Feely J, Robertson D, Island DR. Cimetidine alters plasma catecholamine levels and cortisol and aldosterone excretion. N Engl J Med 1982;306:1054-9.

12 Kenyon CJ, Fraser R, Birnie GG. Dose related in vitro effects of ranitidine and cimetidine on basal and ACTH-stimulated steroidogenesis. Gut 1986;27:1143-6.

13 De Natale G, Vacca M, Prezosi P. Cimetidine and adrenals. Drug Res 1980;30:1635-9.

14 Boidin MP, Erdmann WE, Faithfull NS. The role of ascorbic acid in etomidate toxicity. Eur $J$ Anaesthiol 1986;3:417-20.

15 Hornsby PJ, Harris SE, Aldern KA. The role of ascorbic acid in the function of the adrenal cortex: studies in adrenocortical cells in culture. Endocrinology 1985; 117:1264-71.

16 Boidin MP. Can etomidate cause an addisonian crisis? Acta Anaesthiol Belg 1986;37:165-70. 